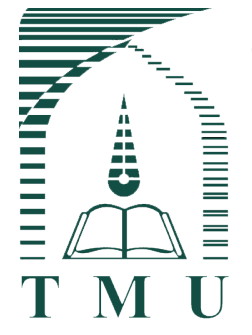

\title{
Macroscopic and Microscopic Survey of the Comparative Effects of Lactobacillus plantarum 299v, Its Supernatant, and Imipenem on Infectious Burn Wound Healing in Rats
}

\section{A R T I C L E I N F O}

\section{Article Type}

Original Research

\section{Authors}

Somayeh Soleymanzadeh Moghadam, $M S c^{1}$

Tahereh Mousavi Shabestari $P h D^{1}$ Fatemeh Heidari, $P h D^{2}$,

Samira Rasouli Koohi, $M S c^{1}$ Mastaneh Afshar, $M S c^{1}$ Roya Omranian, Pharm. $D^{1}$ Maliheh Nobakht, $P h D^{1,3,4^{*}}$

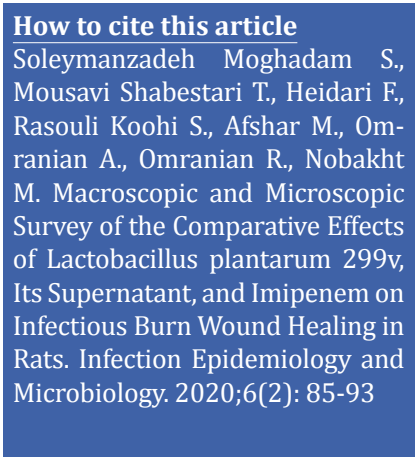

${ }^{1}$ Antimicrobial Resistance Research Center, Institute of Immunology and infection diseases, Iran University of Medical Sciences, Tehran, Iran

2 Cellular and Molecular research Center, Department of Anatomy, Qom University of Medical Science, Qom, Iran

${ }^{3}$ Physiology Research Center, Iran University of Medical Sciences, Tehran, Iran

${ }^{4}$ Department of Anatomy and Cell Biology, school of medicine, Iran University of Medical Sciences, Tehran, Iran

\section{* Correspondence}

Address: Antimicrobial Resistance Research Centre, Rasoul Hospital, Niayesh St, Sattarkhan St, Tehran, Iran.

nobakht@yahoo.com

\section{Article History}

Received: March 05,2020

Accepted: April 15,2020

Published: June 10,2020

\section{A B S T R A C T}

Aims: Burn infections are one of the most common causes of mortality in the world. On the other hand, microbial resistance to antibiotics has caused concern in the medical community. Therefore, controlling burn infections is very important, and using alternative therapies instead of antibiotics could be a good solution to this problem.

Materials \& Methods: Lactobacillus plantarum 299v strains were used in the experiments. Fifty male Wistar rats were prepared, and burn was induced in animals. The burn wounds were inoculated with clinical strains of MDR Pseudomonas aeruginosa in all animals and then treated daily with an eucerin ointment containing different compositions, including $\mathrm{NaCl}$, imipenem, probiotic cell pellet, probiotic supernatant, and probiotic cell pellet + probiotic supernatant. The wound healing process was evaluated in animals after 7 days of treatment. Comparisons between different groups were performed using One-way ANOVA and Turkey's post hoc tests. Findings: After 7 days of treatment, the mean wound size in the probiotic cell pellet group was significantly lower than in the control and imipenem groups. Also, the mean wound size in the probiotic supernatant group was significantly lower than in the imipenem group. Histological parameters related to skin repair in the probiotic cell pellet group was better than in the control and antibiotic groups. Also, inflammation in the probiotic cell pellet group was less than in the control and imipenem groups.

Conclusion: The macroscopic results of this study supported the microscopic results and showed that the mean size of the burn wounds in the probiotic cell pellet group was less than in the control and imipenem groups after 7 days of treatment.

\section{Keywords: Lactobacillus plantarum, Imipenem, Wound healing, Burn.}

\section{CITATION LINKS}

[1] Rybarczyk MM, Schafer JM, Elm CM, Sarvepalli S, Vaswani PA, Balhara KS, et al. A systematic... [2] Tahir SM, Makhdoom A, Awan S, Ali SA. Role of probiotics in the management of ... [3] Barzegari AA, Hashemzaei M, Majdani R, Alihemmati AR. Effects of topical... [4] Benedetta Cinque, Cristina... [5] Church D, Elsayed S, Reid O, Winston B, Lindsay R. Burn... [6] Japoni A, Farshad S, Alborzi A. Pseudomonas... [7] Soleymanzadeh Moghadam S, Fagheei Aghmiyuni Z, Mohammad N, Anissian A, Azimi M, Majidpour A, etal. Survey... [8] Lee MC, Lin LH, HungKL, Wu HY.Oral... [9] Felgner S, Kocijancic D, Frahm M, Weiss S. Bacteria in cancer... [10] Araya M, Morelli L, Reid G, Sanders M, Stanton C, Pineiro M. Joint... [11] Sekhar MS, Unnikrishnan M, Vijayanarayana K, Rodrigues GS, Mukhopadhyay C. Topical... [12] Salaran M, Oryan A, Nikahval B, Kamali A, Ghaemi M, Abbasi-Teshnizi F, et al.... [13] Yuying Liu, Alookaran JJ, Rhoads JM. Probiotics in autoimmune and inflammatory... [14] Lavasani S, Dzhambazov B, Nouri M, Fåk F, Buske S, Molin G, et al. A novel... [15] Barzegari AA, Hashemzaei1 M, Alihemmati AR, Soltani S, Naseri B. Effects... [16] Della Riccia D, Bizzini F, Perilli M, Polimeni A, Trinchieri V, Amicosante G, et al... [17] Al-Mathkhury HJF, Al-Aubeidi HJAR. Probiotic... [18] Guarino A, Canani RB, Spagnuolo MI, Albano F, Di Benedetto L. Oral bacterial therapy reduces... [19] Halper J, Leshin L, Lewis S, Li W. Wound healing and angiogenic properties of supernatants from... [20] Li W, Brackett B, Halper J. Culture... [21] Valdez J, Peral M, Rachid M, Santana M, Perdigon G. Interference... [22] Heydari Nasrabadi M, Tajabadi Ebrahimi M, Dehghan Banadaki Sh, Torabi Kajousangi M, Zahedi F.... [23] Ebrahimi TM, Ouwehand AC, Hejazi MA, Jafari P. Traditional... [24] Goudarzvand M, Rasouli Koohi S, Khodaii Z, Soleymanzadeh Moghadam S. Probiotics ... [25] Greenhalgh DG, Sprugel KH, Murray MJ, Ross R.n... [26] Eroglu E, Agalar F, Altuntas I, Eroglu F. Effects of... [27] Abramov Y, Golden B, Sullivan M, Botros SM, Miller JJ, Alshahrour A, et al... [28] Greenhalgh DG, Spruge KH, Murray MJ, Rosst R... [29] Hansen JE, Jespersen LK... [30] Prince T, McBain AJ, O’Neill CA. Lactobacillus ... [31] Peral MC, Huaman Martinez MA, Valdez... [32] Nhan C, Bezdjia A, Saha S, Prakash S, Nguyen LH, Danie SJ... [33] Simova E, Beshkova D, Angelov A, Hristozova T, Frengova G, Spasov Z. Lactic... [34] Isolauri E, Kirjavainen P, Salminen S. Probioticse... [35] Campana R, Hemert SV, Baffone W.... [36] Sharma J, Chauhan D. Inhibition... [37] Guilfoile P, Alcamo IE. Antibiotic-resistant... [38] Ammann AJ, Beck LS, Deguzman L, Hirabayashi SE, Pun Lee W, McFatridge L, et al. Transforming... [39] Kekkonen RA, Lummela N, Karjalainen H, Latvala S, Tynkkynen S, Järvenpää S, et al. Probiotic... [40] von Schillde MA, Hörmannsperger G, Weiher M, Alpert CA, Hahne H, Bäuerl C, et al. Lactocepin... 


\section{Introduction}

Burn wounds are always a threat to human health and may lead to inability or even death ${ }^{[1]}$. Burn wound infections could cause tissue necrosis if not treated well ${ }^{[2-3]}$. Skin is a natural barrier to invasive pathogens. In burns, the skin barrier is damaged, and the pathogens are ready to enter the wound and colonize it ${ }^{[2]}$. This is especially important when invaders are bacteria that are also resistant to antibiotics ${ }^{[3]}$. Some of the most common microorganisms colonizing and infecting burn wounds include Staphylococcus aureus, Pseudomonas aeruginosa, and fungal pathogens ${ }^{[4-5]}$. P. aeruginosa is a major opportunistic human pathogen which has acquired antimicrobial resistance properties [5-6]. Today, multidrug resistance in bacteria is a sever threat to public health worldwide, and the widespread use of antibiotics play a key role in the appearance of resistance [7]. Given the increase in antibiotic resistance and long duration of burn wound healing, it is important to find new methods such as bacterial therapy for treatment in order to be able to both prevent and heal wounds ${ }^{[3,6]}$ and also to control drug-resistant infections and improve wound healing. The use of bacteria, especially probiotics, in the treatment of some diseases has attracted much attention ${ }^{[8-9]}$. Probiotics are live microorganisms that are useful and safe [10] and could boost the immune system; also, the main metabolites produced by probiotics have anti-inflammatory effects [11-13]. The role of probiotics in controlling both chronic inflammatory diseases and burn infections has been approved in some studies [4, 14-16]. In addition, probiotics could eliminate pathogenic microbes and improve wound healing ${ }^{[12]}$. Lactobacilli are nonpathogenic, Gram-positive bacteria classified as lactic acid-producing probiotics [17]. Some studies have shown that some strains of probiotics may be useful in wound healing ${ }^{[18]}$. Research has shown that Lactobacillus supernatants promote inflammatory responses and angiogenesis and also stimulate proliferation of embryonic cells during the tissue repair in rodents [17, 19-20]. L. plantarum and its products have antibacterial properties and could inhibit the growth of pathogenic microbes such as $P$. aeruginosa ${ }^{[4,12]}$. It has been shown that probiotic therapy could stop bacterial growth after treatment ${ }^{[4]}$. In addition $L$. plantarum does not produce virulence factor and easily surrenders to the host defenses [21]. Also, some studies have indicated its role in accelerating wound healing process [4, 22-23].

Objectives: In this study, the macroscopic and microscopic effects of $L$. plantarum ointment were investigated on infectious burn dermal wound healing in rats.

\section{Materials and methods}

Probiotic preparation: In this study, the probiotic L. plantarum 299v (DSM9843) was used in the experiments. It was incubated in the De Man, Rogosa and Sharpe (MRS) broth medium anaerobically at $37^{\circ} \mathrm{C}$ for 48 to 72 hrs. After growth in MRS broth medium, in order to ensure the purity of probiotic, it was transferred to the MRS agar medium. Then a dilution of $1.5 \times 10^{9} \mathrm{CFU} / \mathrm{mL}$ of bacterium was prepared and kept in sterile conditions at $4^{\circ} \mathrm{C}{ }^{[24]}$.

Probiotic supernatant preparation: For preparation of probiotic supernatant, the dilution of $1.5 \times 10^{9} \mathrm{CFU} / \mathrm{mL}$ of bacterium was centrifuged at $4000 \mathrm{rpm}$ for $10 \mathrm{~min}$. Supernatant and pellet were separated, and the upper liquid was filtered using a $0.22 \mu$-pore-size filter paper to make sure there is no probiotic. Eventually, cell free supernatant and precipitated cells of probiotic were collected and kept at $4{ }^{\circ} \mathrm{C}$ until use.

Animals: Fifty male adult Wistar rats with the age range of eight to ten weeks and the weight of 200 to $250 \mathrm{~g}$ were prepared from the animal Laboratory of Iran University of Medical Sciences. Animals were maintained under controlled conditions with enough water and food in a 12/12 hr light/ dark cycle at $32 \pm 2{ }^{\circ} \mathrm{C}^{[7]}$. 
Induction of second-degree burn wound and inoculation of bacteria: The rats were killed by intraperitoneal injection of xylazine $(10 \mathrm{mg} / \mathrm{kg})$ and ketamine (100 $\mathrm{mg} / \mathrm{kg}$ ). Then the animals' hair on the dorsal areas was shaved and disinfected with $70 \%$ ethanol. In the next step, the dorsal areas of the animals were exposed to a hot steel rod with a temperature of $95^{\circ} \mathrm{C}$ and a diameter of $2 \mathrm{~cm}$ for $10 \mathrm{sec}$. To prevent the animals from suffering and to reduce their pain, after the induction of wounds, ketamine was injected daily. Twenty four hours after the induction of burn wounds, the wounds were inoculated with $1 \mathrm{~mL}$ of MDR Pseudomonas aeruginosa clinical strains resistant to carbapenems $\left(1.5 \times 10^{8}\right.$ $\mathrm{CFU} / \mathrm{mL})^{[4]}$.

Animal grouping and treatment for each group: Twenty-four hours after the induction of infection, all rats were divided into 5 groups $(\mathrm{n}=10$ each) randomly. The wounds in all animals were treated with an eucerin ointment containing different compositions daily for 7 days, and the treatment was performed on each group as follows: the control group received eucerin ointment + $0.9 \% \mathrm{NaCl}(1 \mathrm{~g}: 1 \mathrm{~mL})$, the imipenem group received eucerin ointment + imipenem (1g:1mg), the l.p group received eucerin ointment + probiotic cell pellet $\left(1 \mathrm{~g}: 10^{9} \mathrm{CFU} /\right.$ $\mathrm{mL}$ ), the s group received eucerin ointment + probiotic supernatant (lg: $1 \mathrm{~mL})$, and the l. $p+s$ group received eucerin ointment + probiotic cell pellet + probiotic supernatant (1g: $10^{9} \mathrm{CFU} / \mathrm{mL}: 1 \mathrm{~mL}$ ).

Evaluation of the wound healing process: All rats were sacrificed through anesthesia using an overdose of xylazine after 7 days of treatment, and the evaluations were conducted as follows.

Macroscopic assessment of the wounds: The burn wounds were assessed $24 \mathrm{hrs}$ after the bacterial inoculation or $48 \mathrm{hrs}$ after the induction of burns (before the initiation of treatment: day 0) and again after 7 days of treatment by measuring the wounds size with the naked eye using a ruler.

Microscopic assessment of the wounds: After the rats were killed on the seventh day of treatment, $2 \times 2 \mathrm{~cm}$ of the wound skin tissue was removed. The dermal tissues were fixed with 10\% neutral buffered formalin (NBF) and $8 \% \mathrm{NaCl}$ overnight. Then dehydration process was performed through a series of graded alcohol, and the slices were paraffinized. Then they were cut by a microtome with $2 \mu \mathrm{m}$ thickness and stained with Hematoxylin \& Eosin (H\&E) and trichrome [7, 25-26]. Morphological assessment was performed blindly (in terms of tissue type and treatment type) by a skilled pathologist. The essential histological parameters, including inflammation, granulation tissue formation, collagen deposition, re-epithelialization, and neovascularization, were evaluated with original magnification of $\times 20$. The microscopic assessment was performed using an Olympus photomicroscope (PROVIS AX70, Japan) equipped with a digital camera (DP11, Japan). Trauma was graded histologically based on a 4-point semi-quantitative rating scale as follows: Inflammation(absent, 0; scant,1; moderate,2; abundant,3), amount of granulation tissue formation (absent, 0; a few, 1; moderate, 3; abundant, 4), collagen deposition (absent, 0 ; a few, 1; moderate, 3; abundant, 4), reepithelialization (absent, 0; partial, 1; thin, 2; thick, 4), neovascularization (absent, 0; a few, 1; moderate, 2; many, 3) ${ }^{[27-28]}$.

\section{Statistical analysis}

Data were analyzed by SPSS software, Version 20. Comparisons between different groups were performed using One-way ANOVA and Turkey's post hoc tests. The $p$ value $<.05$ was considered as statistically significant.

\section{Findings}

Wound size examination: The mean size of the wound was measured and evaluated the day before (0) and after 7 days of treatment (Fig. 1). The findings indicated that after 7 days of treatment, the mean wound size in the probiotic cell pellet group was significantly lower than in the control $(p=$ $.001)$ and imipenem groups $(p=.000)$. Also, the mean size of the wound in the probiotic supernatant group was significantly lower than in the imipenem group ( $p=.04)$. 


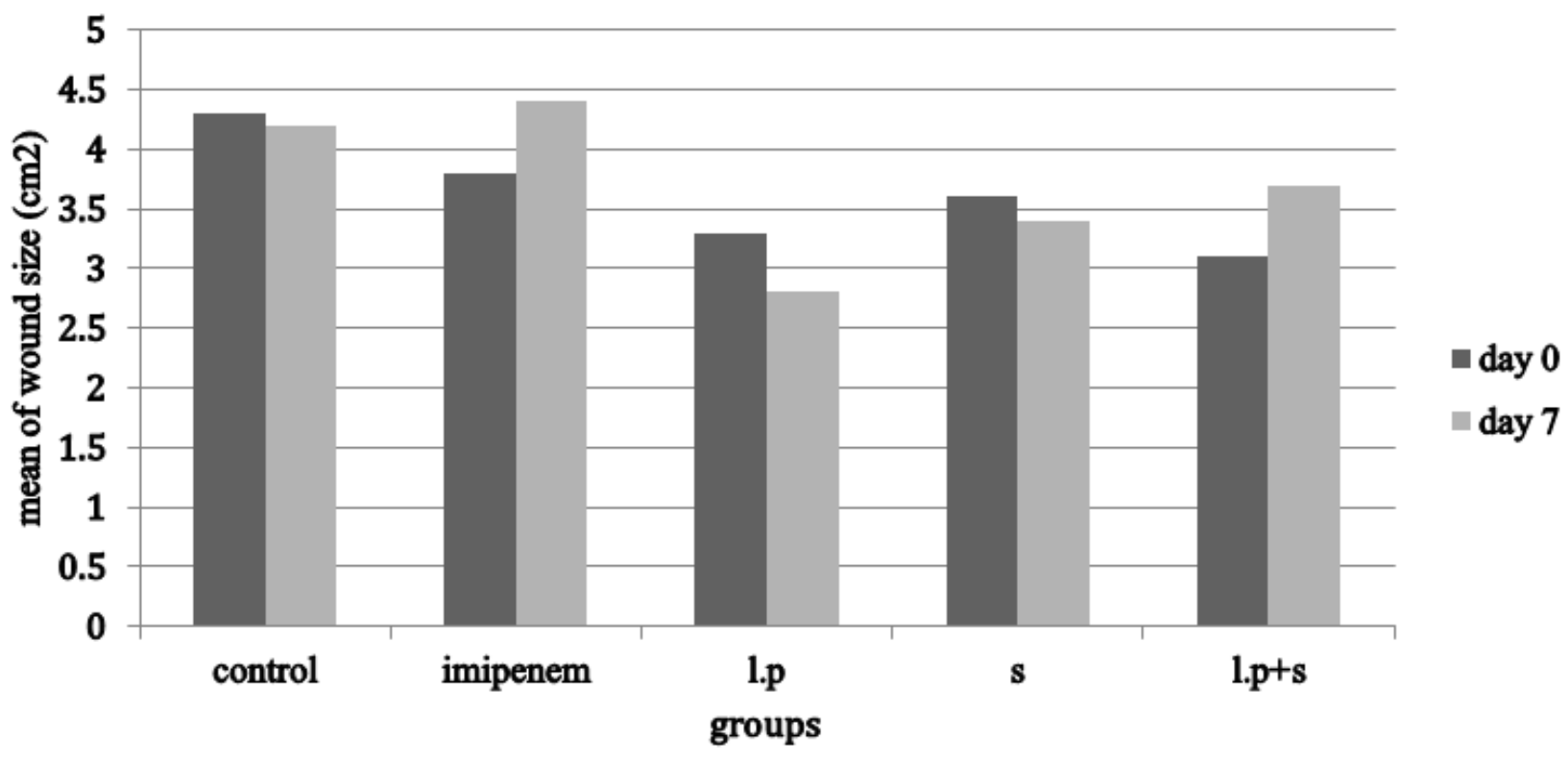

Figure 1) Mean size of the burn wounds in 5 groups $(n=10$ each $)$ after 7 days of treatment.

Since no significant difference was observed between different groups on Day 0 , in order to evaluate the effects of different treatments on wound healing, after 7 days of treatment, the size of the wound was measured again and compared between various groups as follows: According to the results, there were significant differences between the treatment groups, including the l.p and control $(p=.001)$, the l.p and imipenem ( $p$ $=0.000)$, and the $\mathrm{s}$ and imipenem $(p=0.04)$ groups. Statistical method of ANOVA was followed by Tukey's post Hoc test.

Table Guide: control, $\mathrm{NaCl}$; imipenem, antibiotic; l.p, probiotic (L. plantarum 299v) cell pellet; s, probiotic supernatant; l.p+s, probiotic cell pellet + probiotic supernatant. Histological examination: Histological parameters such as inflammation, amount of granulation tissue formation, collagen deposition, re-epithelialization, and neovascularization were evaluated in all burn wound specimens and delaminated based on the histological scoring system (Table 1).

As shown in Table 1 and Figure 1ae, the epithelialization defect was obviously observed in the control group. In this group, re-epithelialization was not completed, and the wound was not closed. In addition, inflammatory cells and fibroblasts infiltration was extensive, and collagen deposition was significant.

In the imipenem group, epithelium defect was observed with necrosis, cellular infiltration was very little, and granulation tissue was observed above the subcutaneous fat. In the probiotic cell pellet group, the re-epithelialization was completed in the wound, and the thickness increased significantly, indicating that the wound was closed in this group. In addition, cellular infiltration was very little, granulation tissue was observed above the subcutaneous fat, vascular tissue was created increasingly in the bed of the wound, and collagen deposition was significant. In the probiotic supernatant group, accumulation of granulation tissue was moderate, and the re-epithelialization and wound closure were completed. In addition, inflammatory cell and fibroblasts infiltration was observed extensively, and there was collagen deposition in this group. Moreover, in the probiotic cell pellet + probiotic supernatant group, the re-epithelialization was completed in the wound, and the thickness in the epithelial of this group was moderate. In addition, inflammatory cell and fibroblasts infiltration and collagen deposition were demonstrated, and granulation tissue with predominant collagen fibers was observed in this group. 
Table 1) The survey of parameters affecting wound healing in the skin after 7 days of treatment in burned rats (based on the histological scoring system)

\begin{tabular}{lccccc|}
\hline \multicolumn{1}{c}{ Group } & Control & Imipenem & l.p & S & l.p+s \\
\hline histologic parameters & 1 & 3 & Score & & 2 \\
Inflammation & 1 & 0 & 3 & 2 & 3 \\
Granulation tissue & 1 & 0 & 3 & 2 & 2 \\
Collagen deposition & 0 & 0 & 3 & 2 & 2 \\
Re-epithelialization & 0 & 0 & 3 & 2 & 3 \\
\hline Neovascularization & & & & 2 & 2 \\
\hline
\end{tabular}

a)

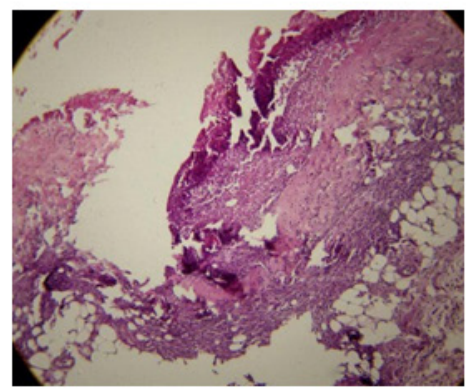

b)

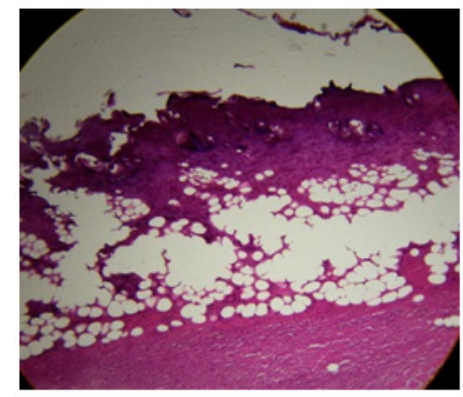

d)

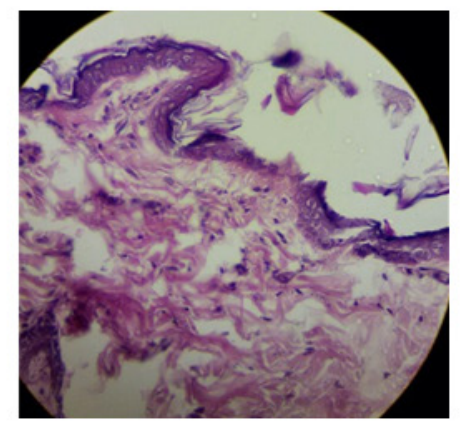

e)

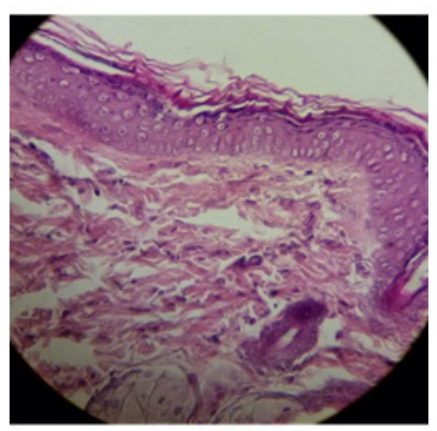

Figure 2) Photomicrograph of skin sections after 7 days of treatment in burned rats by H\&E staining and X20 magnification.

Inflammation and collagen deposition in the control group (a), Extensive inflammation and low granulation tissue in the imipenem group (b), Re-epithelialization, granulation tissue, collagen deposition, neovascularization, and inflammation in the probiotic cell pellet group (c), Re-epithelialization, granulation tissue, collagen deposition, and inflammation in the probiotic supernatant group (d), Reepithelialization, granulation tissue, collagen deposition, and inflammation in the probiotic cell pellet + probiotic supernatant group (e).

\section{Discussion}

In this study, macroscopic and microscopic assessments of the wounds indicated that wound healing in the areas treated with $L$. plantarum were more than in the control and antibiotic groups. Previous research has shown that topical application of lactic acid bacteria as probiotic could prevent the colonization of pathogens and wound infection by different mechanisms [3, 29-30] associated with wound healing.

In the current study, the mean size of the 
burn wounds in the L. plantarum group was less than in the control and antibiotic groups after 7 days of treatment. Also, the mean size of the burn wounds was less in the probiotic cell pellet recipient group in comparison with probiotic supernatant group. In this regard, in a study on patients with second and 3rd-degree burn wounds, Peral et al. (2019) showed that dermal treatment with L. plantarum may reduce the bacterial count in the wounds ${ }^{[31]}$.

Also, Carol Nhan et al. (2017) indicated that $L$. plantarum could reduce the $S$. aureus and $P$. aeruginosa growth in the wounds ${ }^{[32]}$. Moreover, the use of lactic acid bacteria as probiotic may accelerate wound healing process and reduce infection by different mechanisms ${ }^{[29]}$. L. plantarum could accelerate wound healing process by reducing the duration of inflammatory response [33]. Probiotics have the ability to naturally stimulate the skin's immune response, thereby enhancing skin repair and healing ${ }^{[34]}$. Also, one of the functional mechanisms of probiotic is their ability to rival with pathogenic bacteria ${ }^{[35]}$. Therefore, it seems that wound healing is better done using probiotic bacteria. But when bacteria are not present and bacterial supernatant is used, there is no competition between probiotics and pathogens. Although in macroscopic observation, better results were expected in terms of wound closure in the probiotic cell pellet + probiotic supernatant group, the wound tissue analysis results showed epithelial thickness and skin healing. By producing lactic acid, hydrogen peroxide, and acetic acid, probiotics play a key role in inhibiting the pathogens growth ${ }^{[36]}$. In this study, the wound closure was less in the imipenem group than in the control group, while this antibiotic is commonly used in the treatment of burn wounds nowadays. In fact, inappropriate use of antibiotics could cause antibiotic resistance in bacteria ${ }^{[37]}$. However, more research is needed about this issue. In the current study, some skin histological factors were evaluated, and it was found that re-epithelialization, granulation tissue formation, and collagen deposition were better in the probiotic cell pellet group than in the control and imipenem groups. In this regard, Barzegari et al. (2017) indicated that 3,7 , and 14 days after the burn induction, the rate of epithelialization was higher in the L. acidophilus group than in the control group ${ }^{[3]}$.

In another study on the use of L. rhamnosus ointment for second-degree burn wound in rat in 2018, it was determined that $L$. rhamnosus elevated the rate of fibroblastic migration and re-epithelialization in the wound ${ }^{[15]}$. In addition, local application of $L$. plantarum could promote wound healing by enhancing collagen synthesis; also, probiotic could increase the number of fibroblasts and TGF- $\beta$ level. TGF- $\beta$ is an important peptide which controls wound healing, migration of inflammatory cells to the wound, and promotion of collagen [12, 38]. Therefore, L. plantarum may be a safe, effective, and inexpensive alternative to wound healing.

Also, in this study, it was found that inflammation was less in all L. plantarum treated groups compared to the group receiving antibiotic (Table1). This result is in accordance with the results of the previous studies indicating that some strains of probiotics have anti-inflammatory effects ${ }^{[3,39-40]}$. Also, Benedetta Cinque et al. (2011) said that probiotics could increase collagenesis and hyaluronic acid, which aid to reduce inflammation and heal wound ${ }^{[4]}$.

\section{Conclusion}

Overall, the macroscopic results of this study supported the microscopic findings and determined that the mean size of the burn wounds in the L. plantarum group was less than in the control and imipenem groups after 7 days of treatment, and in the same day, histological parameters related to skin repair were better in the probiotic group than in the control and antibiotic groups. Also, inflammation in the probiotic cell pellet group was less than in the control and antibiotic groups.

Acknowledgments: The authors thank Mr. Hossein Noori Mazandarani in animal laboratory of Iran University of Medical Sciences. 
Ethical Permissions: This study performed with ethical code IR.IUMS.REC 1396.30857.

Conflicts of interest: The authors declare they have no conflict of interests.

Authors Contribution: Conceptualization: SSM, MN; Data curation: SSM, MN; Formal analysis: SRK, Funding acquisition: MN; Investigation: All Authors; Methodology: SSM, TMS, FH, SRK, MA; Project administration: $\mathrm{MN}$; Writing-original draft: SSM, RO; Writing-review and editing: SSM, MN.

Fundings: The study was financially supported by Iran University of Medical Sciences with grant number 30857.

Consent to participate: Not applicable.

\section{References}

1. Rybarczyk MM, Schafer JM, Elm CM, Sarvepalli S, Vaswani PA, Balhara KS, et al. A systematic review of burn injuries in low-and middle-income countries: Epidemiology in the WHO-defined African Region. Afr J Emerg Med. 2017; 7(1):30-7.

2. Tahir SM, Makhdoom A, Awan S, Ali SA. Role of probiotics in the management of burns patients,World J Med Sci. 2014; 11(3):417-21.

3. Barzegari AA, Hashemzaei M, Majdani R, Alihemmati AR. Effects of topical treatment of second-degree burn wounds with Lactobacillus acidophilus on the wound healing process in male rats. Pharm Biomed Res. 2017; 3(3):2330.

4. Benedetta Cinque, Cristina La Torre, Esterina Melchiorre, Giuseppe Marchesani, Giovanni Zoccali, Paola Palumbo,et al. Use of Probiotics for Dermal Applications. Probiotics, Microbiology Monographs. 2011.

5. Church D, Elsayed S, Reid O, Winston B, Lindsay R. Burn wound infections. Clin Microbiol Rev. 2006; 19(2):403-34.

6. Japoni A, Farshad S, Alborzi A.
Pseudomonas aeruginosa: Burn infection, treatment, and antibacterial resistance. Iran Red Crescent Med J. 2009; 11(3):244-53.

7. Soleymanzadeh Moghadam S, Fagheei Aghmiyuni Z, Mohammad N, Anissian A, Azimi M, Majidpour A, et al. Survey of the effect of granulocyte-colony-stimulating factor ( $\mathrm{G} \mathrm{CSF}$ ) on bacterial translocation and wound healing in burned mice. Arch Trauma Res. 2019; 8(3):149-54.

8. Lee MC, Lin LH, Hung KL, Wu HY. Oral bacterial therapy promotes recovery from acute diarrhea in children. Acta Paediatr Taiwan. 2001; 42:301-5.

9. Felgner S, Kocijancic D, Frahm M, Weiss S. Bacteria in cancer therapy: Renaissance of an old concept. Int J Microbiol. 2016; 2016: 8451728.

10. Araya M, Morelli L, Reid G, Sanders M, Stanton C, Pineiro M. Joint FAO/ WHO Working Group report on drafting guidelines for the evaluation of probiotics in food. London, Canada: World Health Organization; Food and Agriculture Organization of the United Nations, 2002.

11. Sekhar MS, Unnikrishnan M, Vijayanarayana K, Rodrigues GS, Mukhopadhyay C. Topical, application/ formulation of probiotics: Will it be a novel treatment approach for diabetic foot ulcer? Med Hypotheses. 2014; 82(1):86-8.

12. Salaran M, Oryan A, Nikahval B, Kamali A, Ghaemi M, Abbasi-Teshnizi F, et al. Topical application of Lactobacillus plantarum on burn wound healing in diabetic rats. Iran J Vet Surg. 2019; 14(1);60-72.

13. Yuying Liu, Alookaran JJ, Rhoads JM. Probiotics in autoimmune and inflammatory disorders. Nutrients. 2018; $\quad$ 10(10):1537.

14. Lavasani S, Dzhambazov B, Nouri M, Fåk F, Buske S, Molin G, et al. A novel probiotic 
mixture exerts a therapeutic effect on experimental autoimmune encephalomyelitis mediated by IL-10 producing regulatory $\mathrm{T}$ cells. PLoS One. 2010; 5(2):e9009.

15. Barzegari AA, Hashemzaei1 M, Alihemmati AR, Soltani S, Naseri B. Effects of Lactobacillus rhamnosus (ATCC 7469) ointment on second-degree burn wound in Wistar rat. J Bas Res Med Sci. 2018; 5(1):1-9.

16. Della Riccia D, Bizzini F, Perilli M, Polimeni A, Trinchieri V, Amicosante G, et al. Antiinflammatory effects of Lactobacillus brevis (CD2) on periodontal disease. Oral Dis. 2007; 13:376-85.

17. Al-Mathkhury HJF, Al-Aubeidi HJAR. Probiotic effect of Lactobacilli on mice incisional wound infections. Journal of AlNahrain University. 2008; 11(3):111-6.

18. Guarino A, Canani RB, Spagnuolo MI, Albano F, Di Benedetto L. Oral bacterial therapy reduces the duration of symptoms and of viral excretion in children with mild diarrhea. J Pediatr Gastroenterol Nutr. 1997; 25(5):516-9.

19. Halper J, Leshin L, Lewis S, Li W. Wound healing and angiogenic properties of supernatants from Lactobacillus cultures. Exp Biol Med. 2003; 228(11):1329-37.

20. Li W, Brackett B, Halper J. Culture supernatant of Lactobacillus acidophilus stimulates proliferation of embryonic cells. Exp. Biol. Med. 2005; 230(7):494500.

21. Valdez J, Peral M, Rachid M, Santana M, Perdigon G. Interference of Lactobacillus plantarum with Pseudomonas aeruginosa in vitro and in infected burns: The potential use of probiotics in wound treatment. Clin Microbiol Infect. 2005; 11(6):472-9.

22. Heydari Nasrabadi M, Tajabadi Ebrahimi M, Dehghan Banadaki Sh, Torabi Kajousangi M, Zahedi F. Study of cutaneous wound healing in rats treated with Lactobacillus plantarum on days 1 , 3, 7, 14 and 21. Afr J Pharm Pharmaco. 2011; 5(21):2395-401.

23. Ebrahimi TM, Ouwehand AC, Hejazi MA, Jafari P. Traditional Iranian dairy products: A source of potential probiotic lactobacilli. Afr J Microbiol. 2011; 5(1):207.

24. Goudarzvand M, Rasouli Koohi S, Khodaii Z, Soleymanzadeh Moghadam S. Probiotics Lactobacillus plantarum and bifidobacterium B94: cognitive function in demyelinated model. Med J Islam Repub Iran. 2016; 30:391.

25. Greenhalgh DG, Sprugel KH, Murray MJ, Ross R. PDGF and FGF stimulate wound healing in the genetically diabetic mouse. Am J Pathol. 1990; 136(6):1235-46.

26. Eroglu E, Agalar F, Altuntas I, Eroglu F. Effects of granulocyte-colony stimulating factor on wound healing in a mouse model of burn trauma. Tohoku J Exp Med. 2004; 204(1):11-6.

27. Abramov Y, Golden B, Sullivan M, Botros SM, Miller JJ, Alshahrour A, et al. Histologic characterization of vaginal vs. abdominal surgical wound healing in a rabbit model. Wound Rep Reg. 2007; 15(1):80-6.

28. Greenhalgh DG, Spruge KH, Murray MJ, Rosst R. PDGF and FGF stimulate wound healing in the genetically diabetic mouse. Am J Pathol. 1990; 136(6):1235-46.

29. Hansen JE, Jespersen LK. Wound or tissue dressing comprising lactic acid bacteria. US Patent 0143447 A1, 2010.

30. Prince T, McBain AJ, O’Neill CA. Lactobacillus reuteri protects epidermal keratinocytes from Staphylococcus aureus-induced cell death by competitive exclusion. Appl Environ Microbiol. 2012; 78(15):5119-26.

31. Peral MC, Huaman Martinez MA, Valdez JC. Bacteriotherapy with Lactobacillus plantarum in burns. Int Wound J. 2009; 
6(1):73-81.

32. Nhan C, Bezdjia A, Saha S, Prakash S, Nguyen LH, Danie SJ. Safety of transtympanic application of probiotics in a chinchilla animal model. J Otolaryngol Head Neck Surg. 2017; 46(1):63.

33. Simova E, Beshkova D, Angelov A, Hristozova T, Frengova G, Spasov Z. Lactic acid bacteria and yeasts in kefir grains and kefir made from them. J Ind Microbiol Biotechnol. 2002; 28(1):1-6.

34. Isolauri E, Kirjavainen P, Salminen S. Probiotics: A role in the treatment of intestinal infection and inflammation? Gut. 2002; 50(Suppl 3):54-9.

35. Campana R, Hemert SV, Baffone W. Strain-specific probiotic properties of lactic acid bacteria and their interference with human intestinal pathogens invasion. Gut Pathog. 2017; 9(1):12.

36. Sharma J, Chauhan D. Inhibition of Pseudomonas aeruginosa by antibiotics and probiotics combinations-in vitro study. Europ J Exp Biol. 2014;4(6):10-4. 37. Guilfoile P, Alcamo IE. Antibioticresistant bacteria. Infobase Publishing; 2007.

38. Ammann AJ, Beck LS, Deguzman L, Hirabayashi SE, Pun Lee W, McFatridge L, et al. Transforming growth factor- $\beta$ effect on soft tissue repair. Ann NY Acad Sci. 1990; 593(1):124-34.

39. Kekkonen RA, Lummela N, Karjalainen H, Latvala S, Tynkkynen S, Järvenpää S, et al. Probiotic intervention has strainspecific anti-inflammatory effects in healthy adults. World J Gastroenterol. 2008; 14(13):2029-36.

40. von Schillde MA, Hörmannsperger G, Weiher M, Alpert CA, Hahne H, Bäuerl C, etal. Lactocepin secreted by Lactobacillus exerts anti-inflammatory effects by selectively degrading proinflammatory chemokines. Cell Host Microbe. 2012; 11(4):387- 96. 